\title{
Power Conversion System Operation to Reduce the Electricity Purchasing Cost of Energy Storage Systems
}

\author{
Jun-Mo Kim ${ }^{1}{ }^{1}$, Jeong Lee ${ }^{2}$, Jin-Wook Kim ${ }^{2}$, Junsin $\mathrm{Yi}^{2}$ and Chung-Yuen Won ${ }^{2, *}$ \\ 1 Interdisciplinary Program in Photovoltaic System Engineering, Sungkyunkwan University, \\ Suwon 16419, Korea; ksho4807@skku.edu \\ 2 Department of Electrical and Computer Engineering, Sungkyunkwan University, Suwon 16419, Korea; \\ leejeong1@skku.edu (J.L.); wooks415@skku.edu (J.-W.K.); junsin@skku.edu (J.Y.) \\ * Correspondence: woncy@skku.edu; Tel.: +82-031-290-7164
}

Citation: Kim, J.-M.; Lee, J.; Kim, J.-W.; Yi, J.; Won, C.-Y. Power Conversion System Operation to Reduce the Electricity Purchasing Cost of Energy Storage Systems. Energies 2021, 14, 4728. https:// doi.org/10.3390/en14164728

Academic Editor: Gian Giuseppe Soma

Received: 29 June 2021

Accepted: 31 July 2021

Published: 4 August 2021

Publisher's Note: MDPI stays neutral with regard to jurisdictional claims in published maps and institutional affiliations.

Copyright: (c) 2021 by the authors. Licensee MDPI, Basel, Switzerland. This article is an open access article distributed under the terms and conditions of the Creative Commons Attribution (CC BY) license (https:// creativecommons.org/licenses/by/ $4.0 /)$.

\begin{abstract}
A strategy to operate a power conversion system (PCS) to minimize the electricity rate of an energy storage system (ESS) is formulated. The ESS operation method is determined considering the power management system (PMS). The primary functions include peak-cut, peak-shifting, and frequency regulation typically related to electricity rates. Thus, the battery is charged and discharged when the price is low and high, respectively, thereby monetizing the battery. However, the ESS incurs a high cost for the batteries and PCS. Therefore, ESSs that reuse electric vehicle (EV) batteries are being actively developed. Many researchers have attempted to maximize the profit of ESSs by developing algorithms to calculate the optimal ESS capacity by performing a power load analysis of electricity consumers. An ESS selected based on this calculation can be operated through the PMS. This ESS can use the battery state of charge $(S o C)$, ranging from $10-90 \%$, to conduct a feasibility analysis using the net present value, which reflects the current electricity rate. This feasibility analysis is performed considering the difference between the initial investment cost of the ESS and the profit obtained from the power generation of the ESS. In South Korea, many policies have been implemented to encourage the installation of ESSs. The ESS promotion policy was implemented until 2020 to reduce the electricity rate, including the contracted capacity of batteries. However, since 2021, this policy has been transformed to reduce the electricity rate based on the daily maximum power generation. Thus, the conventional method of increasing the battery capacity is not suitable, and the profitability should be increased using limited batteries. For ESSs, PCSs composed of single and parallel structures can be used. When installing a large capacity ESS, a PCS using silicon ( $\mathrm{Si}$ ) is adopted to reduce the unit cost of the PCS. The unit price of a silicon carbide (SiC) device has recently decreased significantly. Thus, in this study, a PCS using this SiC device was developed. Moreover, an algorithm was formulated to minimize the electricity rate of the ESS, and the operation of a modular type PCS based on this algorithm was demonstrated.
\end{abstract}

Keywords: power conversion system; energy storage system; power management system; net present value

\section{Introduction}

With the widespread use and diversification of renewable energy sources (RES) and increase in the related investment, the proportion of new and renewable energy in conventional power systems is gradually increasing; wind and solar energy are the most rapidly growing new and renewable energy sources worldwide [1]. However, these energy sources have high intermittency and their output cannot be adjusted; thus, the increased proportion of these resources in the system results in a supply demand imbalance and frequency and voltage instabilities [2]. In this context, the power system can be stabilized by limiting the output of new and renewable energy. However, the generated power may decrease involuntarily, reducing the profitability of the new and renewable energy business. This decrease in profitability can also increase the operating cost of conventional power systems. 
The most fundamental method to maintain the stability of a power system while minimizing the output limitation is to use an energy storage system (ESS) [3]. By combining new and renewable energy and ESSs, the intermittency of existing renewable energy can be reduced and transmission load can be increased. This combined system can increase new and renewable energy revenue by charging and discharging the battery when the system's marginal price is low and high, respectively. However, the fabrication cost of ESSs is high, due predominantly to the batteries and power conversion system (PCS) $[4,5]$. Governments have actively implemented policies to ensure business feasibility using incentive policies associated with the introduction of new and renewable energy sources to increase the proportion of those sources in the system. A difference in revenue is generated by introducing separate weights depending on the renewable energy certificate, power generation source, and installation location of the new and renewable energy source [6].

Accordingly, many studies have attempted to optimize ESS capacity to maximize profitability. Study [7] used ESS to reduce the intermittent characteristics of photovoltaic (PV), an intermittent energy source, and study [8] described the installation and operation techniques in electric vehicle (EV) fast-charging stations by combining PV and ESS. Furthermore, studies $[9,10]$ optimized battery capacity. Adopting the optimized capacity helps ensure the revenue of the power generation business in constructing the ESS. Furthermore, combined forms of PV and ESS are widely used in assumptions [11].

As PV and ESS-linked systems, among many energy sources, are being frequently used for self-generation, and many supportive policies are being implemented, considerable research has been conducted to minimize the electricity bill incurred by such systems [12]. An objective function to reduce the electricity rate has been formulated through linear programming (LP) [13], PCS efficiency considerations, and mixed integer LP (MILP), in which the battery charging/discharging state is separately defined and reflected in the constraint conditions $[14,15]$. Capacity optimization of renewable energy sources was performed using MILP [16]. Study [17] applied MILP considering the efficiency of the ESS used in a microgrid (MG) connected to several RES.

For complex objective functions, the genetic algorithm (GA) [18] and Tabu search (TS) [19] algorithm have been adopted. Study [20] combined dynamic programming and the GA to control the amount of charge/discharge power and optimize the quantity of ESSs required. Study [21] used an algorithm combining TS and particle swarm optimization for intermittent RES and battery-linked systems. Electricity bill minimization was conducted in these studies. However, an ESS's power converter efficiency is not constant as in study [22]. As the efficiency is not constant even considering the charging and discharging efficiency of the ESS, there are many errors in capacity optimization.

Therefore, to consider the efficiency, a specific efficiency of the PCS is required. These algorithms can establish an objective function by combining the objective functions to minimize the electricity rate and base rate. The criteria for judging the state of the ESS include the current and time during charging and discharging, depending on the state of the battery. When the ESS is operated using the objective function of minimizing the electricity rate and base rate, the number of sections in which a transient state occurs may be increased during ESS operation. The lithium-ion batteries used in ESSs may be degraded due to the state of charge $(S o C)$, depth of discharge, temperature, C-rate, and operating time [23]. This degradation affects the state of health of the battery and thus the operation time of the ESS. Furthermore, PCS has different efficiencies depending on the charge/discharge mode and the magnitude of the current [24]. Constant efficiency is required to use the objective function considering efficiency.

This study formulates a strategy for PCS operation by adopting the objective function of minimizing the electricity rate of the ESS, considering the PCS efficiency. The PCSs of the ESS are divided into those with single and multi-parallel structures. If the capacity of the ESS is significantly higher than that of the PCS, the PCS can be operated at its maximum capacity. However, this method increases the initial investment cost of the ESS. A limited battery is used in such scenarios with a capacity similar to that of the PCS, leading to a 
limited charging/discharging C-rate of the battery. If a system is implemented with a single PCS, the efficiency during charging and discharging differs considerably. This study addresses this problem by considering PCS efficiency to minimize the electricity rate of the ESS. Furthermore, we propose an algorithm that enables the PCS to be operated at the same efficiency regardless of load, in which the difference in efficiency occurs during charging and discharging and at the maximum efficiency.

\section{PCS Operation Strategy}

This section describes the ESS operation strategy. An ESS is typically used to charge/ discharge the battery when electricity rates are low and high, respectively. This study considers the electricity rates for South Korea, considering the ESS discount system based on the policy of new and renewable energy sources $[25,26]$.

For industrial use, the ESS converts the profit that can be obtained from power generation into the net present value using the objective function of minimizing the electricity rate and base rate. Figure 1 illustrates the circuit diagram for ESS operation adopted in this study. A combined form of the ESS and PV is used. ESSs are frequently operated in combination with other new and renewable energy sources [27]. Such systems are used in combination with intermittent energy sources to lower the associated intermittency.

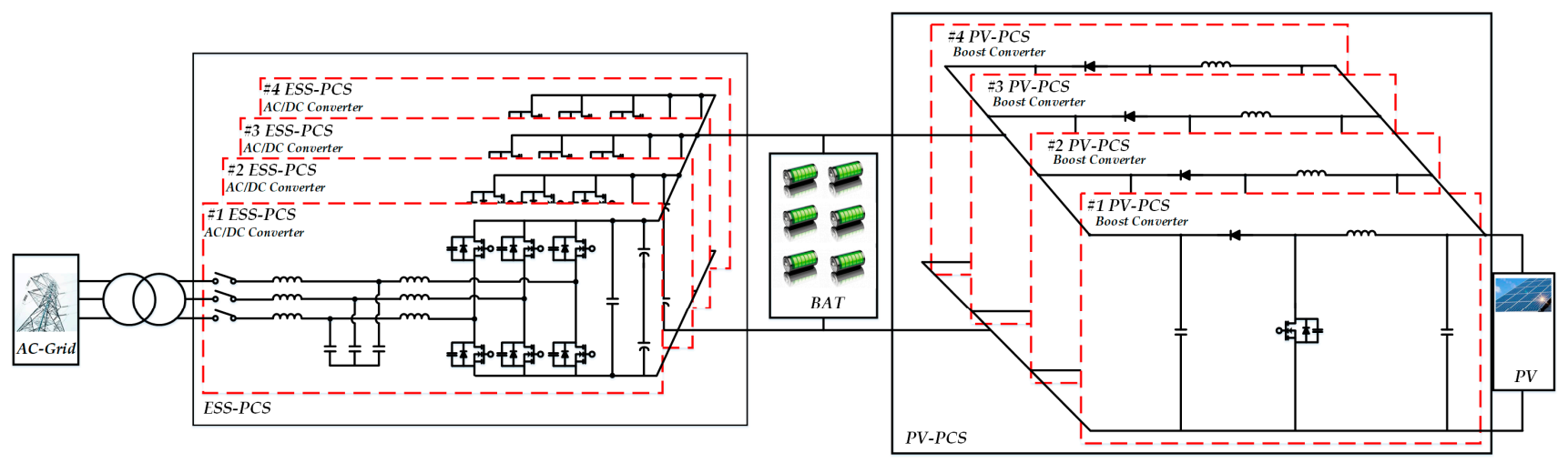

Figure 1. ESS-PCS and PV-PCS circuit.

Figure 2 illustrates the ESS installation capacity and classification according to installation purpose in South Korea. ESS developed $4.7 \mathrm{GW}$, of which approximately 33\% of $1.58 \mathrm{GW}$ used PV-linked systems. Table 1 presents the renewable energy credit (REC) policies of PV in effect in South Korea. The current policy also assigns the most weight to the linkage between PV and ESS. Therefore, in this paper, the system is constructed with an ESS linked to PV.
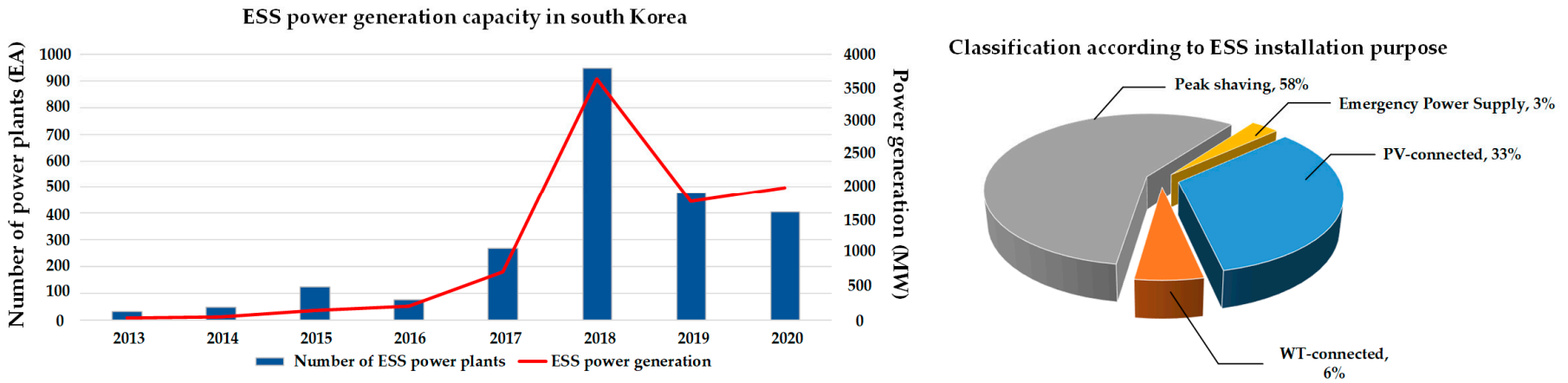

Figure 2. ESS power generation capacity and classification according to ESS installation purpose in South Korea. 
Table 1. South Korea's REC weight.

\begin{tabular}{|c|c|c|c|c|}
\hline \multirow{2}{*}{ Technology Types } & \multirow{2}{*}{ Description } & \multicolumn{3}{|c|}{ REC Multipliers } \\
\hline & & 2012 & 2015 & 2020 \\
\hline \multirow{3}{*}{ General land excluding forest land } & Less than $100 \mathrm{~kW}$ & \multirow{3}{*}{$0.7-1.2$} & 1.2 & 1.2 \\
\hline & From $100 \mathrm{~kW}$ & & 1.0 & 1.0 \\
\hline & Above 3000 kW & & 0.7 & 0.7 \\
\hline Solar in forest land & - & 0.7 & $0.7-1.2$ & 0.7 \\
\hline \multirow{2}{*}{ Building-integrated solar } & $3000 \mathrm{~kW}$ or less & \multirow{3}{*}{1.5} & 1.5 & 1.5 \\
\hline & Above $3000 \mathrm{~kW}$ & & 1.0 & 1.0 \\
\hline Floating solar & - & & 1.5 & 1.5 \\
\hline Solar for self-use & - & & 1.0 & 1.0 \\
\hline ESS facility (solar-connected) & $2016-2020.6$ & - & 5.0 & 5.0 \\
\hline
\end{tabular}

The following subsections describe South Korea's electricity rate and ESS discount systems and the techniques to minimize the ESS electricity rate and achieve PCS operation for ESSs.

\subsection{Electricity Rate System and ESS Discount System}

Table 2 summarizes the electricity rate system in South Korea, and Table 3 presents the associated schedule, which shows that the electricity rates are distributed hourly across a day [25]. High-Voltage (A), High-Voltage (B), and High-Voltage (C) are classified based on the incoming voltage for electricity customers. The incoming voltages of High-Voltage (A), High-Voltage (B), and High-Voltage (C) are $22.9 \mathrm{kV}, 154 \mathrm{kV}$, and $345 \mathrm{kV}$ or higher, respectively. Options I, II, and III can be arbitrarily selected by an electricity consumer in formulating an electricity supply contract. Typically, if the electricity usage time is high or low for a month, consumers prefer Option III or I, respectively.

Table 2. Industrial electric charges.

\begin{tabular}{|c|c|c|c|c|c|c|}
\hline \multirow{2}{*}{\multicolumn{2}{|c|}{ Classification }} & \multirow{2}{*}{$\begin{array}{l}\text { Demand Charge } \\
(\mathrm{KRW}(\mathbf{W}) / \mathbf{k W})\end{array}$} & \multicolumn{4}{|c|}{ Energy Charge (KRW(W)/kWh) } \\
\hline & & & Time Period & Summer & Spring/Fall & Winter \\
\hline \multirow{9}{*}{ High-Voltage (A) } & \multirow{3}{*}{ Option I } & \multirow{3}{*}{7220} & low-peak & 61.6 & 61.6 & 68.6 \\
\hline & & & mid-peak & 114.5 & 84.1 & 114.7 \\
\hline & & & high-peak & 196.6 & 114.8 & 172.2 \\
\hline & \multirow{3}{*}{ Option II } & \multirow{3}{*}{8320} & low-peak & 56.1 & 56.1 & 63.1 \\
\hline & & & mid-peak & 109.0 & 78.6 & 109.2 \\
\hline & & & high-peak & 191.1 & 109.3 & 166.7 \\
\hline & \multirow{4}{*}{ Option III } & \multirow{4}{*}{9810} & low-peak & 55.2 & 55.2 & 62.5 \\
\hline & & & mid-peak & 108.4 & 77.3 & 108.6 \\
\hline & & & high-peak & 178.7 & 101.0 & 155.5 \\
\hline & & & low-peak & 60.0 & 60.0 & 67.0 \\
\hline \multirow{8}{*}{ High-Voltage (B) } & \multirow[t]{2}{*}{ Option I } & \multirow[t]{2}{*}{6630} & mid-peak & 112.3 & 82.3 & 112.3 \\
\hline & & & high-peak & 193.5 & 112.6 & 168.5 \\
\hline & \multirow{3}{*}{ Option II } & \multirow{3}{*}{7380} & low-peak & 56.2 & 56.2 & 63.2 \\
\hline & & & mid-peak & 108.5 & 78.5 & 108.5 \\
\hline & & & high-peak & 189.7 & 108.8 & 164.7 \\
\hline & \multirow{4}{*}{ Option III } & \multirow{3}{*}{8190} & low-peak & 54.5 & 54.5 & 61.6 \\
\hline & & & mid-peak & 106.8 & 76.9 & 106.8 \\
\hline & & & high-peak & 188.1 & 107.2 & 163.0 \\
\hline \multirow{9}{*}{ High-Voltage (C) } & & \multirow{3}{*}{6590} & low-peak & 59.5 & 59.5 & 66.4 \\
\hline & \multirow[t]{3}{*}{ Option I } & & mid-peak & 112.4 & 82.4 & 112.0 \\
\hline & & & high-peak & 193.3 & 112.8 & 168.6 \\
\hline & & \multirow{3}{*}{7520} & low-peak & 54.8 & 54.8 & 61.7 \\
\hline & \multirow[t]{2}{*}{ Option II } & & mid-peak & 107.7 & 77.7 & 107.3 \\
\hline & & & high-peak & 188.6 & 108.1 & 163.9 \\
\hline & \multirow{3}{*}{ Option III } & \multirow{3}{*}{8090} & low-peak & 53.7 & 53.7 & 60.6 \\
\hline & & & mid-peak & 106.6 & 76.6 & 106.2 \\
\hline & & & high-peak & 187.5 & 107.0 & 162.8 \\
\hline
\end{tabular}


Table 3. Time zone classification.

\begin{tabular}{ccc}
\hline Classification & $\begin{array}{c}\text { Summer/Spring/Fall } \\
\text { (Jun.-Aug.)/(Mar.-May.)/(Sep.-Oct.) }\end{array}$ & $\begin{array}{c}\text { Winter } \\
\text { (Nov.-Feb.) }\end{array}$ \\
\hline low-peak & $23: 00-09: 00$ & $23: 00-09: 00$ \\
mid-peak & $09: 00-10: 00$ & $09: 00-10: 00$ \\
& $12: 00-13: 00$ & $12: 00-17: 00$ \\
high-peak & $17: 00-23: 00$ & $20: 00-22: 00$ \\
& $10: 00-12: 00$ & $10: 00-12: 00$ \\
& $13: 00-17: 00$ & $17: 00-20: 00$ \\
\end{tabular}

South Korea is promoting various supportive policies to expand the ESS market. A representative example is the ESS electricity rate discount system. This discount system, which is summarized in Tables 4 and 5, has been in effect since 2016.

Table 4. ESS discount system (period: 2017-2020).

\begin{tabular}{|c|c|}
\hline Classification & Detail \\
\hline Additional savings on base rate & $\begin{array}{l}\{(\text { Discharge during peak load time weekday) } \div \\
\quad(\text { number of weekdays } \times 3 \mathrm{~h})\} \times 3 \text { times } \times \\
\text { differential application of discount amount }\end{array}$ \\
\hline Light load charge discount & $\begin{array}{l}50 \% \text { discount on ESS charging fee } \times \\
\text { differential application of discount amount }\end{array}$ \\
\hline \multicolumn{2}{|c|}{$\begin{array}{l}\text { ※ Differential application of discount amount } \\
\text { - Ratio of ESS battery capacity to contract power of electricity consumers } \\
\text { - } 10 \% \text { or more: } 1.2 \text { times the discount amount } \\
\text { - } 5 \% \text { or more to less than } 10 \%: 1.0 \text { times the discount amount } \\
\text { - Less than } 5 \%: 0.8 \text { times the discount amount }\end{array}$} \\
\hline
\end{tabular}

Table 5. ESS discount system (period: 1 January 2021 - 31 March 2026).

\begin{tabular}{cc}
\hline Classification & Detail \\
\hline Additional savings on base rate & $\{($ Discharge during peak load time weekday $) \div$ \\
Light load charge discount & (number of weekdays $\times 3 \mathrm{~h})\}$ \\
\hline
\end{tabular}

The ESS electricity rate discount system presented in Table 4 is implemented. To benefit from additional reduction in the base rate, the discharge amount during the maximum load time is of significance; thus, the power management system (PMS) is operated according to operation plans such as peak-shaving type and time-shift type ESS operation.

\subsection{Minimized Electricity Bills for ESS}

According to the electricity rate system, electricity rates vary depending on the time interval and load, and the electricity rate of the ESS can be reduced depending on the discharge amount during the maximum load period. The operation during the maximum load (high-peak load) is related to the PCS capacity and battery in the ESS. Typically, the ESS is operated in the region above a certain load to reduce the peak load. Thus, an additional reduction in the base rate can be achieved as mentioned previously by performing the operation from the base load area. The peak load area typically corresponds to sections from $10 \mathrm{~h}$ to $12 \mathrm{~h}$ and from $13 \mathrm{~h}$ to $17 \mathrm{~h}$, which correspond to the sections with the maximum PV generation. Thus, PV generation and ESS discharge must be simultaneously performed. This study incorporates PCSs that charge/discharge the ESS and charge the batteries using the PV, as shown in Figure 1. Thus, the profit that can be obtained from new and renewable energy sources is determined by the PCS capacity of the ESS. The conventional 
discount policy for ESS includes the battery capacity to reduce electricity bills. However, the maximum power per day is important in the current policy that is based only on the daily power generation. The maximum daily power generation of the ESS is determined by the PCS capacity. Figure 3 illustrates the calculation of the PCS capacity according to the peak load. As shown in Figure 3, the minimum SoC discharge of the battery is performed starting from power generation at a certain load and time interval. If the PCS capacity is higher than that of the battery, the operation ends after a brief discharge. Conversely, if the PCS capacity is lower, the profitability of the ESS decreases.

$$
\begin{gathered}
P_{E S S}=\sum_{d=1}^{D} \sum_{t=1}^{T}\left[P_{\text {Load }}^{d, t}-P_{\text {cut }}^{d, t}\right]=\sum_{d=1}^{D} \sum_{t=1}^{T}\left[P_{\text {shaving }}^{d, t}\right][\mathrm{kWh}] \\
P_{E S S}<\sum_{d=1}^{D} \sum_{t=1}^{T}\left(P_{\text {cut }}^{d, t}-P_{\text {Load }}^{d, t}\right)
\end{gathered}
$$

where

$P_{\text {Load }}^{d, t}=$ load in time interval $t$ on day $d$.

$P_{\text {shaving }}^{d, t}=$ load compensated by ESS at $t$ on $d$.

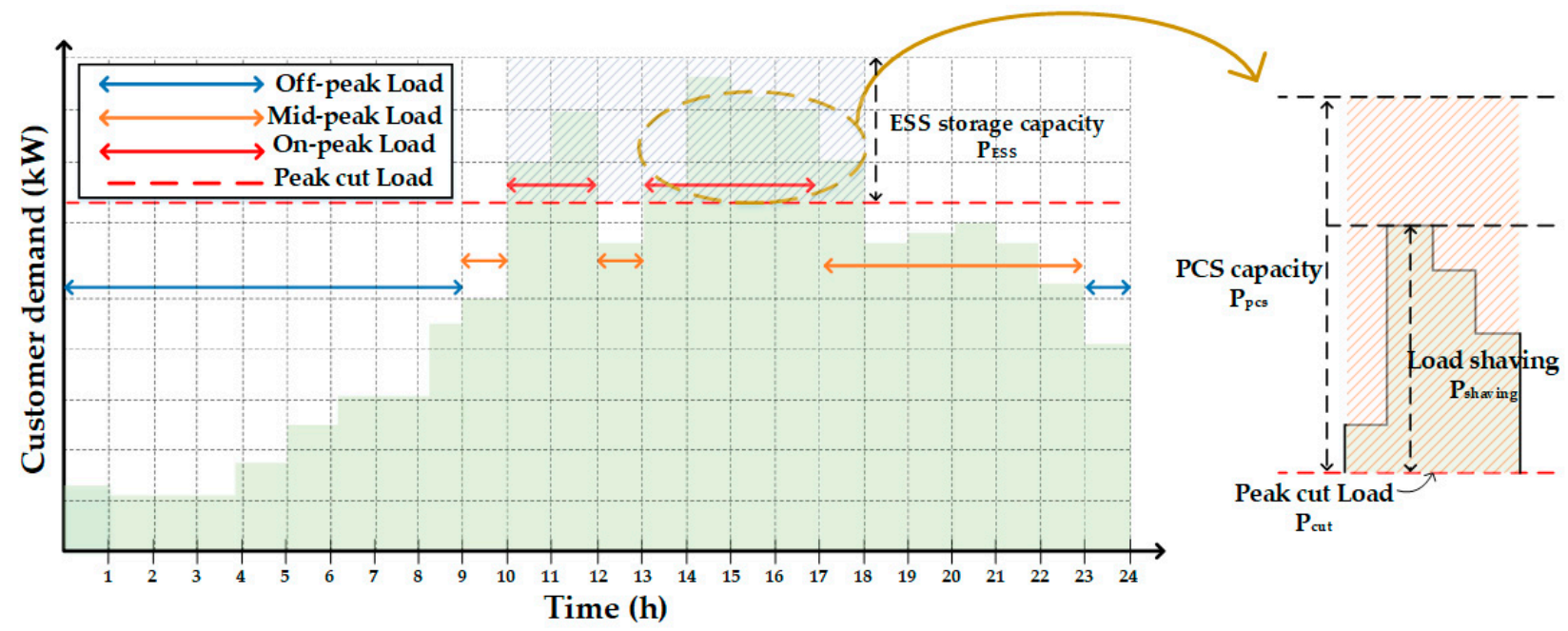

Figure 3. Estimation of PCS capacity according to the peak load.

As shown in Figure 3, power is compensated by discharging the ESS above a peak load threshold. It is difficult to infer the exact load due to instantaneous changes in the actual load curve. However, the load area at a certain time interval is the same. Thus, the equivalence of load can be inferred based on a certain time interval. In the case of peakshaving type ESS, most of the discharge is performed at a high-peak load. Thus, an objective function can be determined for minimizing the electricity rate at each time interval.

$$
J_{\min -T}=\sum_{d=1}^{D} \sum_{t=1}^{T}\left[C^{d, t} \times P^{d, t}\right]
$$

where

$C^{d, t}=$ electricity rate in $t$ on $d$.

$P^{d, t}=$ power for applied charge in $t$ on $d$.

$$
\begin{aligned}
& P^{d, t}=d^{d, t}+P_{E S S}^{d, t} \\
& S o C^{d, t}=S o C^{d, t-1}+\left|P_{P C S_{-} \eta}\right| \times \frac{P_{E S S}^{d, t} \times \frac{24}{T}}{P_{E S S}^{C a p}} \\
& S o C^{D, T}=S o C_{\text {init }}=\alpha \times\left(S o C_{\text {max }}-S o C_{\text {min }}\right)
\end{aligned}
$$

where 
$d^{d, t}=$ load in $t$ on $d$.

$P_{E S S}^{d, t}=$ ESS charging and discharging power in $t$ on $d$.

SoC $C^{d, t}=S o C$ at $t$.

$P_{P C S_{-} \eta}=$ PCS charging and discharging efficiency of the ESS.

$P_{E S S}^{C a p}=$ full capacity of the ESS.

$$
\begin{aligned}
& P_{E S S \_ \text {min }} \leq P_{E S S}^{d, t} \leq P_{E S S \_ \text {max }} \\
& S o C_{\text {min }} \leq S o C^{d, t} \leq S_{0} C_{\text {max }} \\
& P_{E S S}^{d, t}=P_{E S S, \text { cha }}^{d, t}-P_{E S S}^{d, t} \\
& 0 \leq P_{E S S, \text { cha }}^{d, t} \leq y^{d, t} \times P_{E S S, \text { cha }}^{\max } \quad 0 \leq P_{E S S, d i s}^{d, t} \leq z^{d, t} \times P_{E S S, \text { dis }}^{\max } \\
& 0 \leq y^{d, t}+z^{d, t} \leq 1 \\
& y^{d, t}=\left\{\begin{array}{l}
1, \text { if the ESS is charged, } \\
0,
\end{array} \quad \forall t\right. \\
& z^{d, t}=\left\{\begin{array}{l}
1, \text { if the ESS is discharged, } \\
0,
\end{array} \quad \forall t\right.
\end{aligned}
$$

where

$P_{E S S, \text { cha }}^{d, t}=$ PCS charging power of the ESS at $t$ on $d$.

$P_{E S S, d i s}^{d, t}=$ PCS discharging power of the ESS at $t$ on $d$.

$y^{d, t}=$ binary variable representing the ESS charging state at $t$ on $d$.

$z^{d, t}=$ binary variable representing the ESS discharging state at $t$ on $d$.

In Equation (2), the amount of power is represented by $P^{d, t}$, which is defined as shown in Equation (3) to express the battery $S o C^{d, t}$ of the ESS. To operate the ESS, charging/discharging can be performed between the maximum and minimum values of the $S o C^{d, t}$. However, in the case of domestically installed ESSs, the $S o C^{d, t}$ range is limited. The SoC is limited to a maximum value of $80 \%$ and $90 \%$ for ESSs installed indoors and outdoors, respectively. As shown in Equation (3), the PCS cannot be accurately expressed in terms of the $S o C^{d, t}$ because the charging and discharging efficiencies of the PCS are different. Thus, Equation (3) must be modified to represent various charging and discharging efficiencies, as indicated in Equation (5).

$$
S o C^{d, t}=S o C^{d, t-1}+\frac{P_{E S S, \text { cha }}^{d, t} \times \frac{24}{T}}{P_{E S S}^{C a p}} \times\left(\frac{1}{\eta_{\text {cha }}}\right)-\eta_{d i s} \times \frac{P_{E S S, d i s}^{d, t} \times \frac{24}{T}}{P_{E S S}^{\text {Cap }}}
$$

where

$P_{E S S, \text { cha }}^{d, t}=$ PCS charging power of the ESS at $t$ on $d$.

$P_{E S S, d i s}^{d, t}=$ PCS discharging power of the ESS at $t$ on $d$.

$\eta_{\text {cha }}=$ PCS charging efficiency of the ESS.

$\eta_{d i s}=$ PCS discharging efficiency of the ESS.

The next step is to minimize the base rate. The base rate is related to the base electricity rate, as described in the previous section. These rates are determined depending on the contracted status of the user.

$$
J_{\min -M}=\sum_{m=1}^{M}\left(C_{o_{-} \text {base }} \times p_{\max , m}\right)
$$

where

$C_{O_{-} \text {base }}=$ Contracted base rate.

$P_{\max , m}=$ Maximum power consumption in the m-month contracted capacity. 
In Equation (6), the maximum power per month is multiplied by the base rate, which can be represented in hours and days, as in the previous equation. In this case, Equation (6) can be rewritten as Equation (7), involving a product of the base electricity rate.

$$
\min , P_{\max , m}=\min \sum_{d=1}^{D} \sum_{t=1}^{T}\left(P^{d, t}-P_{\text {mean }}^{d}\right)^{2}
$$

where,

$P_{\text {mean }}^{d}=$ average power consumption on $d$.

Equation (7) can be expressed as the sum of the objective functions for minimizing the electricity rate for each time period and base rate, as indicated in Equation (8). Note that this objective function has a quadratic form, and the charging and discharging efficiencies of the PCS of the ESS cannot be separately applied.

$$
\min , P_{\max , m}=\min \sum_{d=1}^{D} \sum_{t=1}^{T}\left\{\left(P^{d, t}-P_{\text {mean }}^{d}\right)^{2}+\left(C^{d, t} \times P^{d, t}\right)\right\}
$$

The MILP shown in Equation (8) cannot be considered for minimizing the base rate due to its quadratic form. Thus, the ESS operation is performed by arbitrarily calculating the target peak power to be saved. In this context, the MILP is disadvantageous in that the operation is performed by setting an arbitrary target value rather than an optimal solution for the ESS operation. To overcome these shortcomings, in this study, the ESS operation is defined through MILP considering the PCS efficiency based on the reduced ESS capacity through quadratic programming $(\mathrm{QP})$.

Specifically, the appropriate capacity of the ESS is calculated by applying the basic rate minimization equation based on Equation (7), and the electricity rate for the appropriate capacity of the ESS is minimized by reflecting the contracted electricity rate. Finally, the electricity rate is minimized using Equation (2). Thus, the ESS electricity rate is minimized by performing the ESS operation using the MILP that reflects the previously determined PCS efficiency.

\subsection{Algorithm for PCS Operation}

As mentioned previously, the electricity rate of the ESS is determined by considering the PCS efficiency. Thus, the electricity rates of the ESS differ according to the PCS efficiency. This study considered a two-level AC/DC converter using silicon carbide ( $\mathrm{SiC}$ ) MOSFETs in four-parallel frameworks. Thus, the number of modules can be selected considering the required power depending on the battery SoC. Figure 4 shows the circuit diagram of the ESS-PCS. Each PCS module transmits the temperature, voltage, and current status to the main controller to verify the status of each PCS.

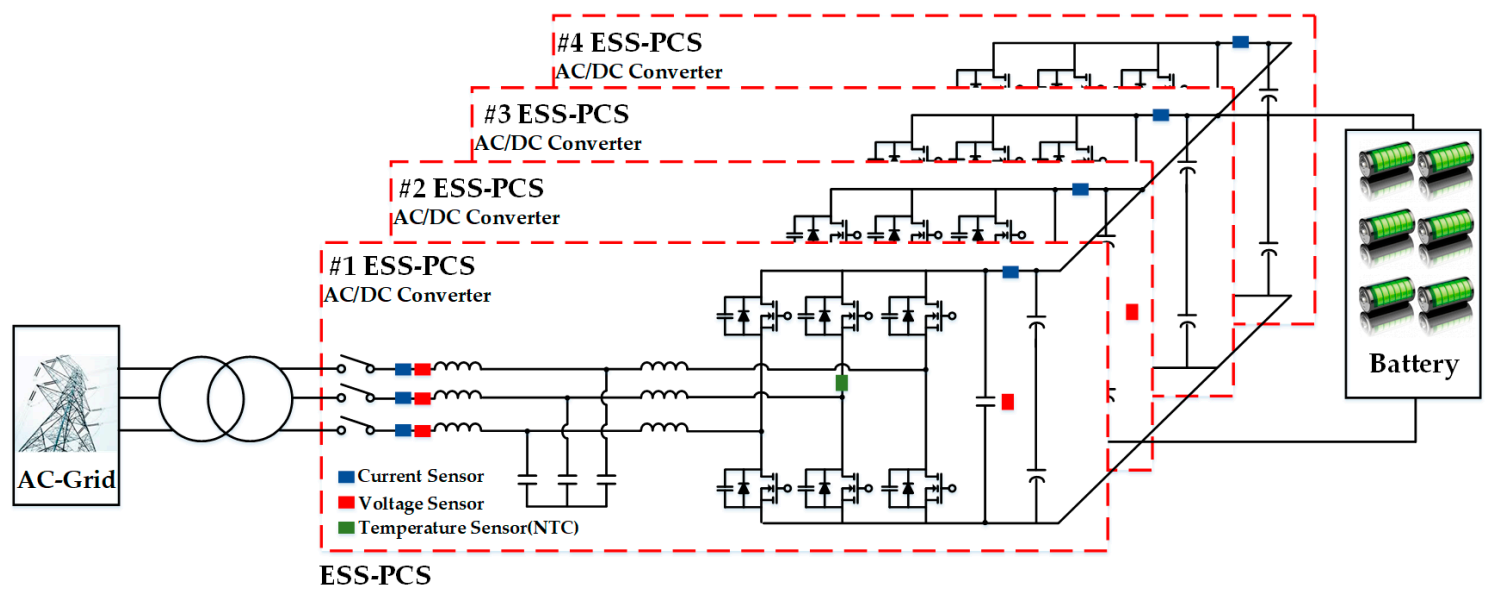

Figure 4. ESS-PCS circuit diagram. 
Certain problems occur when a system is configured with a multi-parallel PCS, such as the higher initial investment cost of the ESS and relatively low maximum efficiency. However, the implementation of a multi-parallel system is advantageous in that the same efficiency is maintained in the entire load area and the ESS can be operated even when a single module fails. Considering these advantages, this study adopts an ESS with a PCS involving four-parallel frameworks. This system operates such that the module specific to a certain capacity operates, and current gradually increases [28,29]. In this framework, any deviation in the operating time of the PCS may result in a difference in the lifespan. To minimize this deviation, this study selects a module based on the temperature and operating time of each module.

Figure 5 shows the simplified PCS operation algorithm that includes six steps: (1) In the operation algorithm based on the electricity rate of the ESS, the charging/discharging operation is determined considering the objective function. (2) The total operating time of each PCS, from $\mathrm{PCS}_{\mathrm{O}-1}$ to $\mathrm{PCS}_{\mathrm{O}-4}$, is compared and stored. (3) The temperature of each PCS, from $\mathrm{PCS}_{\mathrm{T}-1}$ to $\mathrm{PCS}_{\mathrm{T}-4}$ is measured. (4) Each priority is considered to determine whether they are the same PCS. If not, the PCS with the shortest operating time and that with the second lowest temperature are selected. (5) The charging/discharging current magnitude of the battery is calculated according to the objective function to determine the number of PCS modules and perform the operation. (6) The PCS operation is terminated after being implemented in the minimum to maximum SoC range to the target $S o C$.

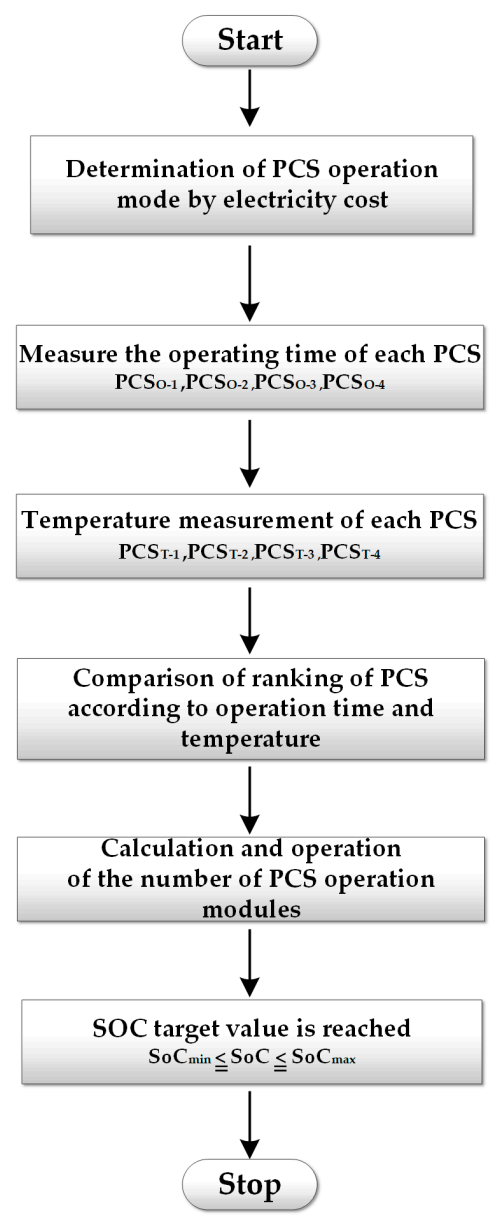

Figure 5. Simplified PCS operation algorithm.

Figure 6 shows the process flow of the algorithm for comparing the PCS operating time and temperature. The temperature measurement is initiated with the priority of the PCS determined depending on the operation time. A two-level ac/dc converter operates bi-directionally and typically exhibits a high efficiency. Thus, if the temperature rises to 
$40{ }^{\circ} \mathrm{C}$, which is a set criterion, the priority is transferred to the next PCS. The priority can be assigned based on the operation time of the PCS to minimize the deviation in the operation time of the multi-parallel PCS.

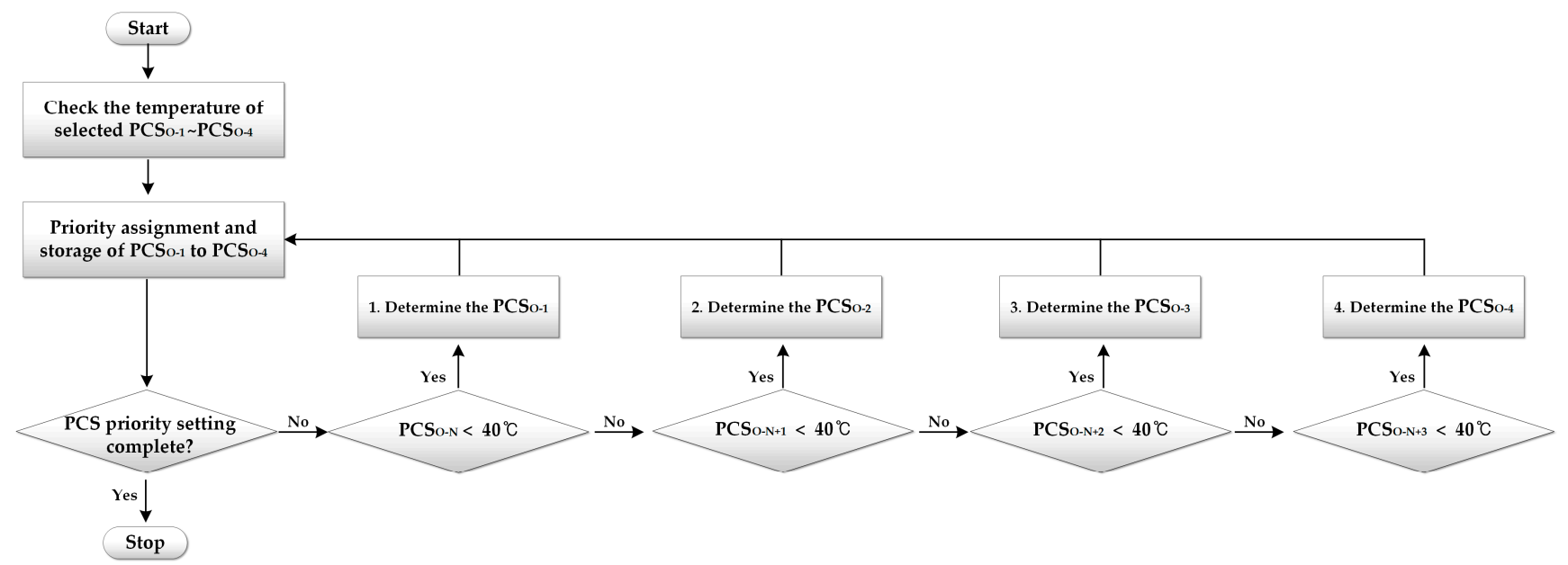

Figure 6. PCS operating time and temperature comparison algorithm.

Figure 7 shows the process flow of the algorithm to obtain the maximum C-rate and maximum operating time of the PCS during charging and discharging, operated based on the previously determined objective function. By minimizing the ESS electricity rate, the charging and discharging time of the ESS and current magnitude can be calculated. An ESS operated with a minimized electricity rate has a relatively small maximum load time. Thus, due to the relatively high charging time, the battery should be charged at a maximum C-rate of 0.5 . However, in a certain section, the operation time is approximately 2 to $3 \mathrm{~h}$ at a high C-rate. In this section, the reduction in the base rate is maximized via operation for up to $25 \mathrm{~min}$ at the maximum $3 \mathrm{C}$-rate.

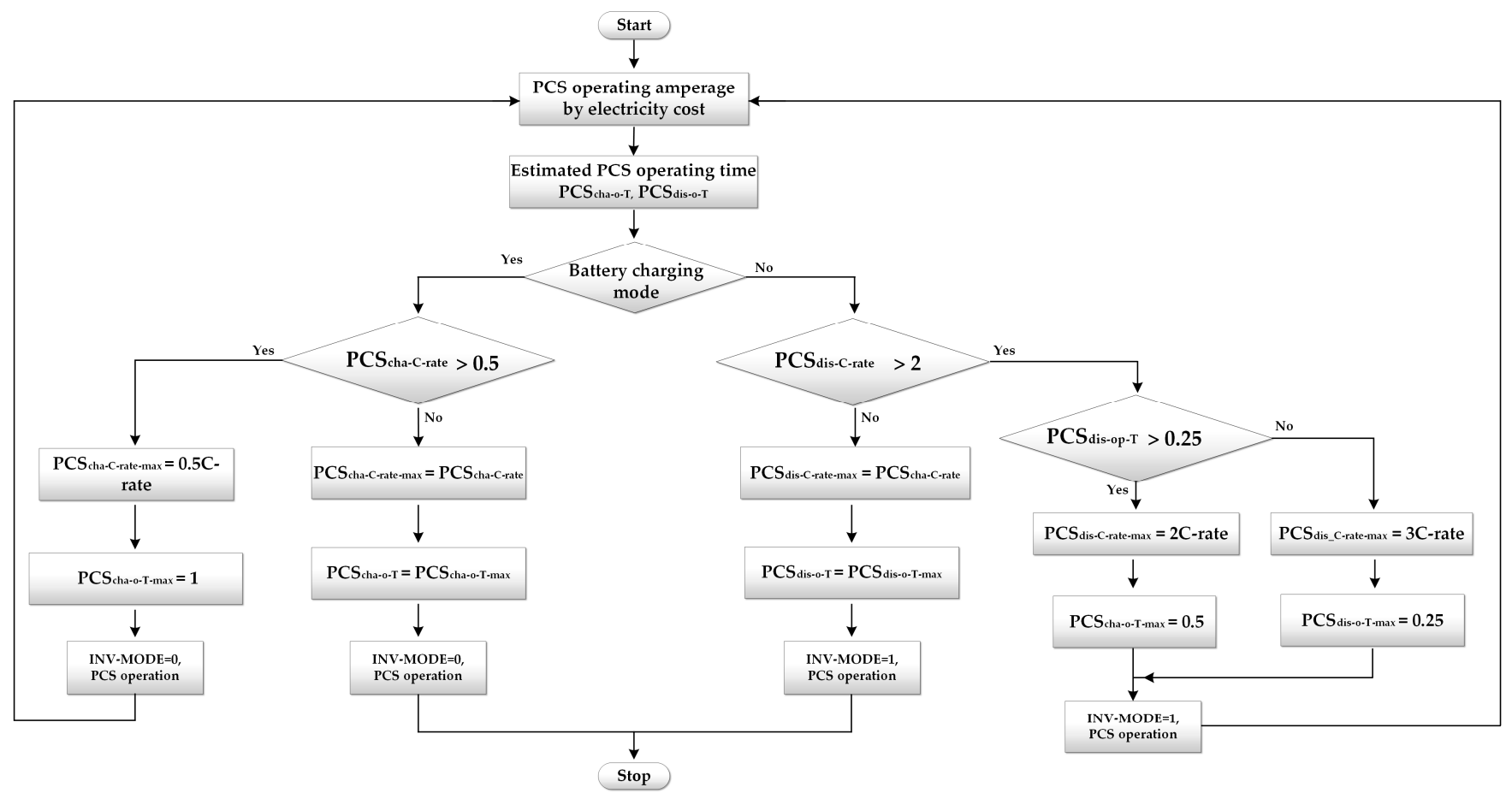

Figure 7. C-rate and maximum operation time algorithm of PCS. 
In this study, the ESS is operated using this algorithm. The battery is charged at a C-rate of up to 0.5 , and the PCS operation time is relatively high. Conversely, the battery is discharged with a high C-rate and low PCS operation time. $\mathrm{PCS}_{\mathrm{O}-1}$ to $\mathrm{PCS}_{\mathrm{O}-4}$ can be selected according to the previously selected maximum C-rate and operating time, while considering the efficiency curve of the designed PCS.

The algorithm shown in Figure 6 is used to obtain information such as the charging/discharging mode, maximum C-rate, and maximum operating time of the battery. Figure 8 illustrates the calculation of the operating current of the PCS based on the obtained information and subsequent operation of the PCS by selecting the number of modules according to the current. As the PCS operates based on the ESS electricity rate, the charging/discharging operation time varies. Thus, the PCS operates in the units of hours and minutes during charging and discharging, respectively. As the maximum load occurs for a relatively short time, a section exists in which the PCS is operated at an instantaneously high C-rate. Because the capacity of one PCS is designed to be $12.5 \mathrm{~kW}$, the PCS operates with a maximum current of approximately $31 \mathrm{~A}$. Due to the use of the limited battery, a difference in the C-rate occurs. Therefore, the PCS efficiency varies.

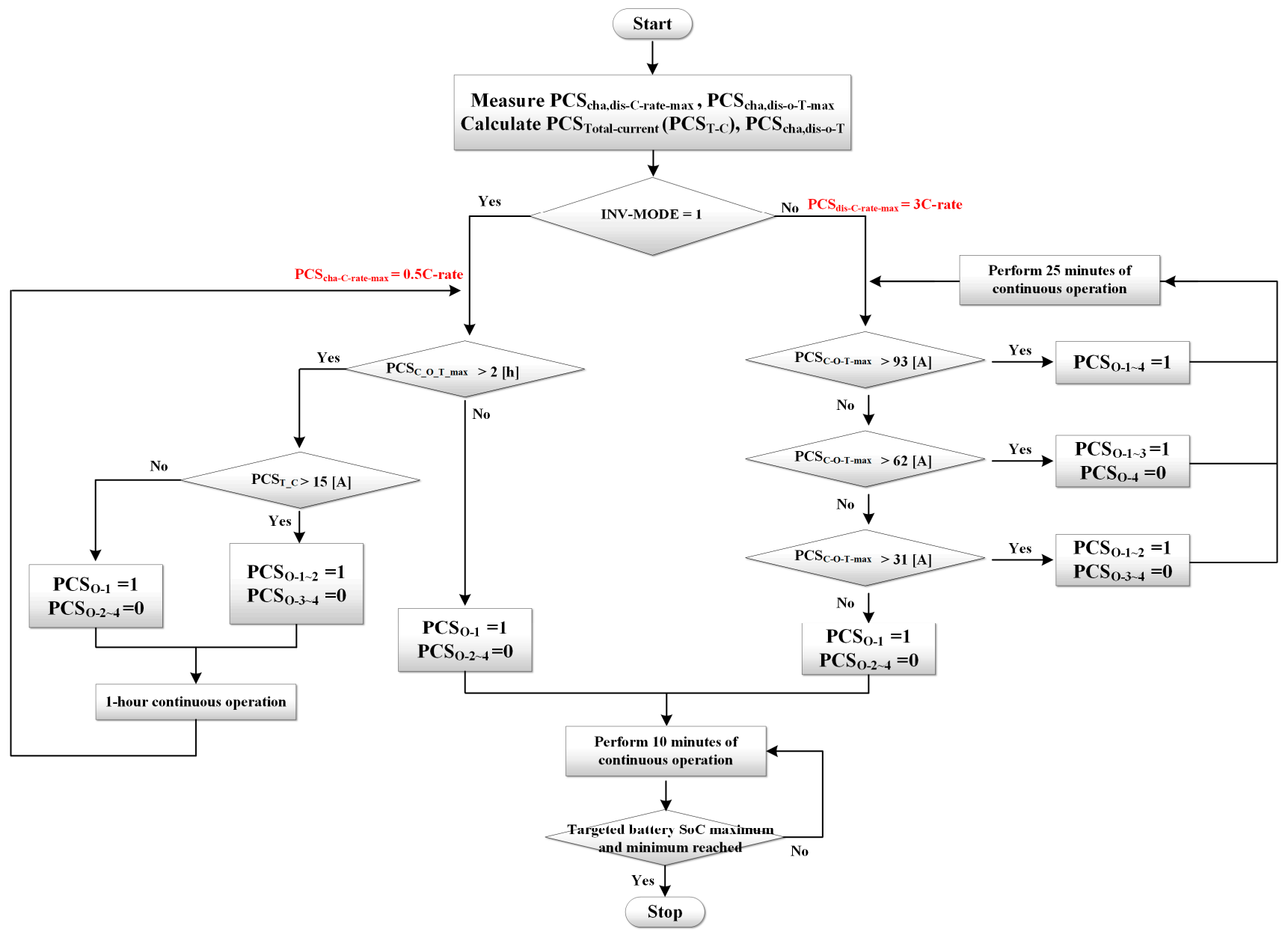

Figure 8. PCS Operation Algorithm.

This study proposes an electricity rate minimization algorithm considering this charging/discharging efficiency and an algorithm to enable the PCS operation with the maximum efficiency during charging/discharging. 


\section{Experiment Results}

Figure 9 shows the experiment setup for validating the ESS operation method. The PCS in this study includes four-parallel modules with a capacity of $12.5 \mathrm{~kW}$ (total PCS capacity of $50 \mathrm{~kW}$ ). Table 6 presents the specifications of one PCS module. The PV is configured with four modules, and the circuit is composed of a boost converter. The capacity of one module in the boost converter is $7.5 \mathrm{~kW}$, with a total capacity of up to $30 \mathrm{~kW}$. The PV is used for charging the battery.

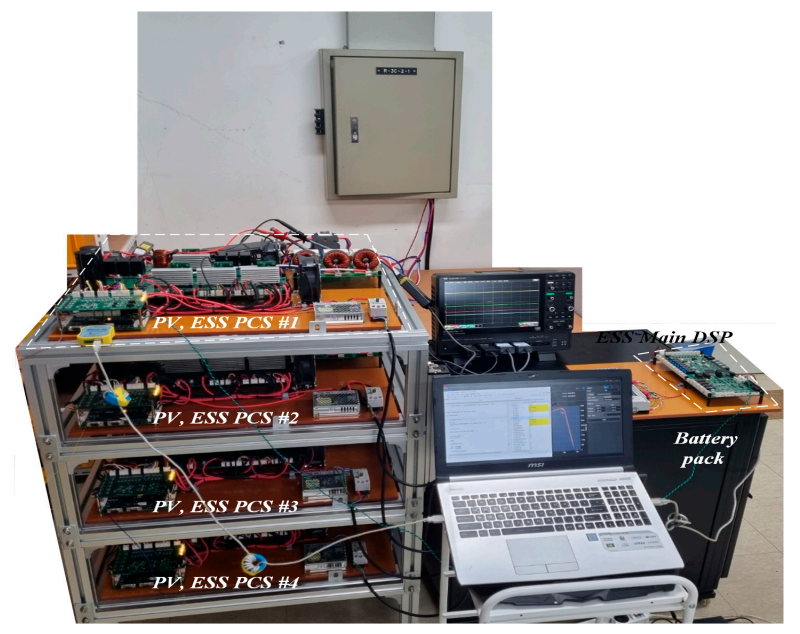

Figure 9. Experimental setup to implement the ESS operation algorithm.

Table 6. Specifications of the ESS PCS two-level ac/dc converter 1 module.

\begin{tabular}{cccc}
\hline Parameter & Value (Unit) & Parameter & Value (Unit) \\
\hline Input Voltage (AC_Grid) & $220(\mathrm{~V})$ & Output Capacitor & $250(\mathrm{uF})$ \\
DC_Link Voltage & $400(\mathrm{~V})$ & Switching Frequency & $50(\mathrm{kHz})$ \\
Output Current (max) & $31.1(\mathrm{~A})$ & Two-Level ac/dc Converter & Power Device \\
\hline
\end{tabular}

The battery is $108 \mathrm{LiFePO}_{4}(3.2-3.7 \mathrm{~V})$ configured in series. In the algorithm shown in Figure 8, the PCS is operated at a C-rate of 0.5 with a total charging current of $20.75 \mathrm{~A}$ and maximum discharging current of $124.59 \mathrm{~A}$. The objective function is formulated based on the PCS efficiency. Thus, the PCS efficiency of one module during charging/discharging should be determined. Table 7 presents the efficiencies in the different modes of the PCS constituting the ESS in this study. In the inverter mode, the maximum efficiency is $97.6 \%$, and a similar efficiency is observed in all areas. In the converter mode, the maximum efficiency is $97.35 \%$, and a decrease in the efficiency is observed above a certain load. However, the PCS operates at approximately $30-60 \%$ in the load section due to the maximum C-rate of 0.5 adopted in charging the battery. As this study adopts a PCS with $\mathrm{SiC}$ elements, the efficiency is higher than that of the conventional PCS. Moreover, this PCS can achieve a high power density by using a higher switching frequency compared to that of Si.

Figure 10 shows the measured efficiency of a single $50 \mathrm{~kW}$-PCS and four-module 12.5 kW-PCS. The modular PCS exhibits a higher maximum efficiency than that of the single PCS. In addition, using a modular PCS, a similar efficiency is attained in all areas. In this study, the power device of the PCS is configured as C3M0045065D (SiC MOSFET). Despite the recent decrease in the unit price of TO-247 type $\mathrm{SiC}$ devices, the price of a modular $\mathrm{SiC}$ device is relatively high. Thus, the PCS with a large-capacity modular SiC device is more expensive than the modular PCS constructed in this study. 
Table 7. Measured PCS 1 module efficiency according to the mode.

\begin{tabular}{ccc}
\hline \multirow{2}{*}{ Load $\mathbf{( \% ) ~ o f ~} \mathbf{1 2 . 5} \mathbf{k W}) \mathbf{( \% )}$} & \multicolumn{2}{c}{ Efficiency $\mathbf{( \% )}$} \\
\cline { 2 - 3 } & Inverter Mode & Converter Mode \\
\hline 5 & 93 & 80 \\
10 & 96 & 92 \\
20 & 97.1 & 96 \\
30 & 97.6 & 97.3 \\
40 & 97.4 & 97.35 \\
50 & 97.5 & 96.9 \\
60 & 97.45 & 96.85 \\
70 & 97.35 & 96.5 \\
80 & 97.3 & 96.3 \\
90 & 97.25 & 96.3 \\
100 & 97.15 & 95.5 \\
\hline
\end{tabular}

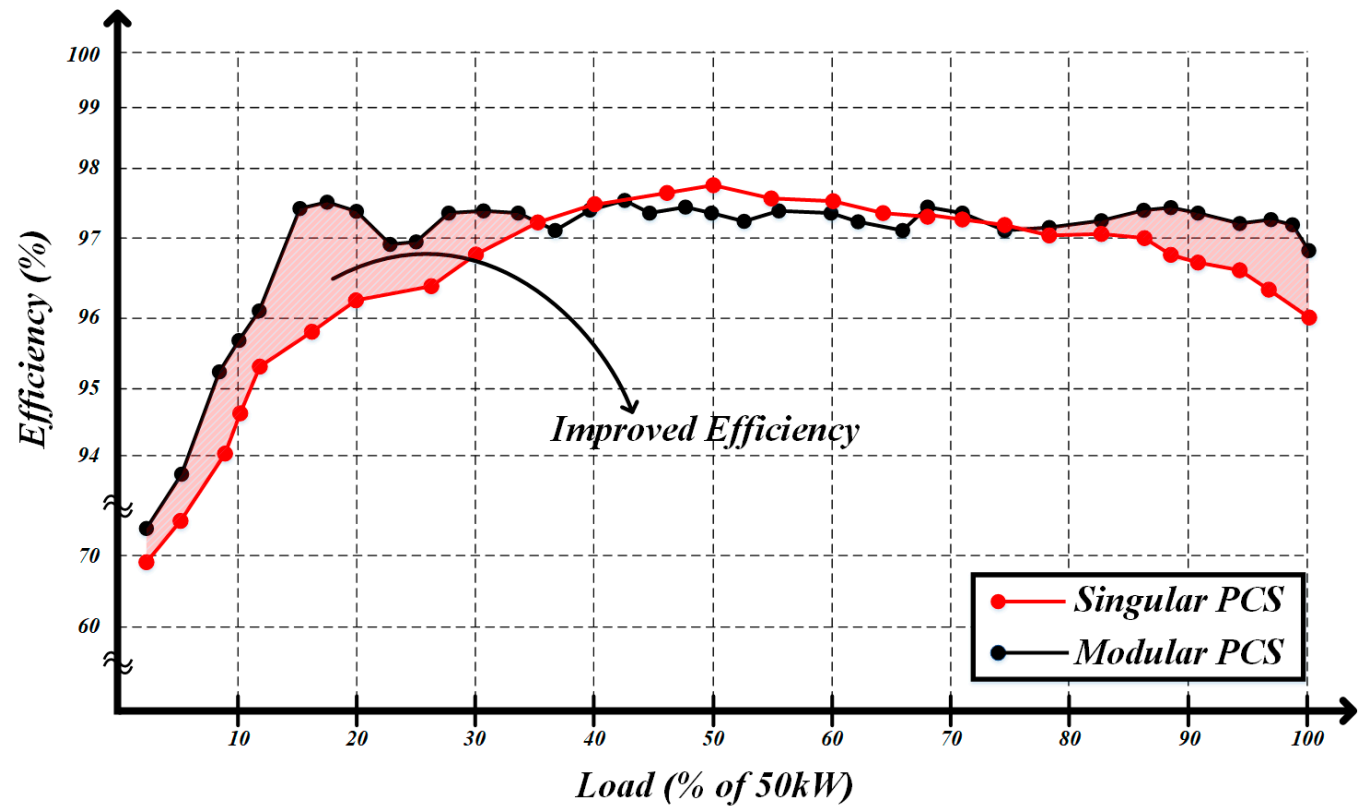

Figure 10. Efficiency measurement for single and modular PCSs.

As the TO-247 device package is used in this study, the temperature results must be considered. The SiC MOSFET used in this study is rated at $650 \mathrm{~V}$ and $50 \mathrm{~A}$. However, because the temperature, which depends on the operating method and incurred loss, can lower the rated current, the change in the temperature is evaluated. Figure 11 shows the temperature measured in different modes and at the maximum $\mathrm{C}$-rate values. The temperature measurement is performed after $3 \mathrm{~h}$ continuous operation at the maximum C-rate. The maximum temperature $\left(60.1^{\circ} \mathrm{C}\right)$ is attained in the inverter mode, and the corresponding rated current is approximately $45 \mathrm{~A}$.

Figure 12 shows the experimental waveform of charging the battery using two PCS modules. Both modules are used to charge the battery at the maximum C-rate. Figure 13 shows the waveform of module disconnection due to a decrease in the battery charging current caused by an increased SoC during battery charging. 


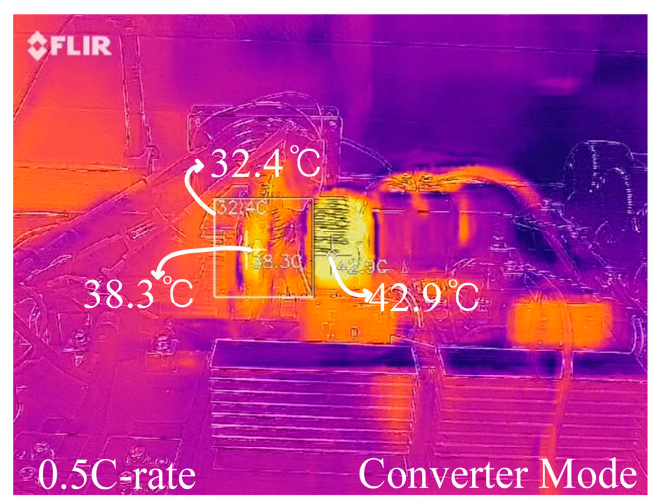

(a)

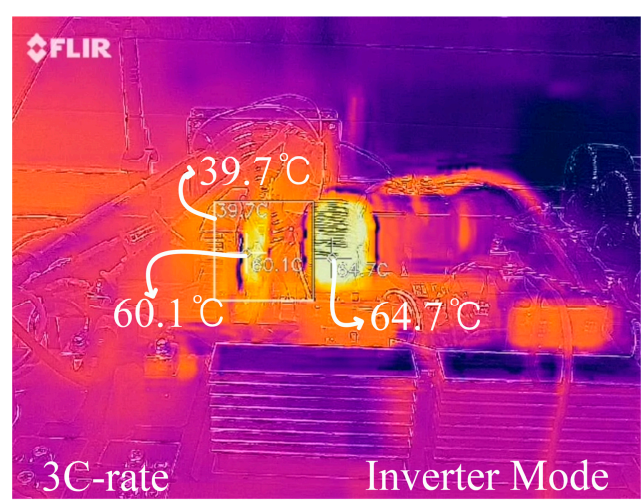

(b)

Figure 11. Power device temperature during maximum C-rate operation in different modes: (a) converter mode (maximum C-rate is 0.5 ), and (b) inverter mode (maximum C-rate is 3).

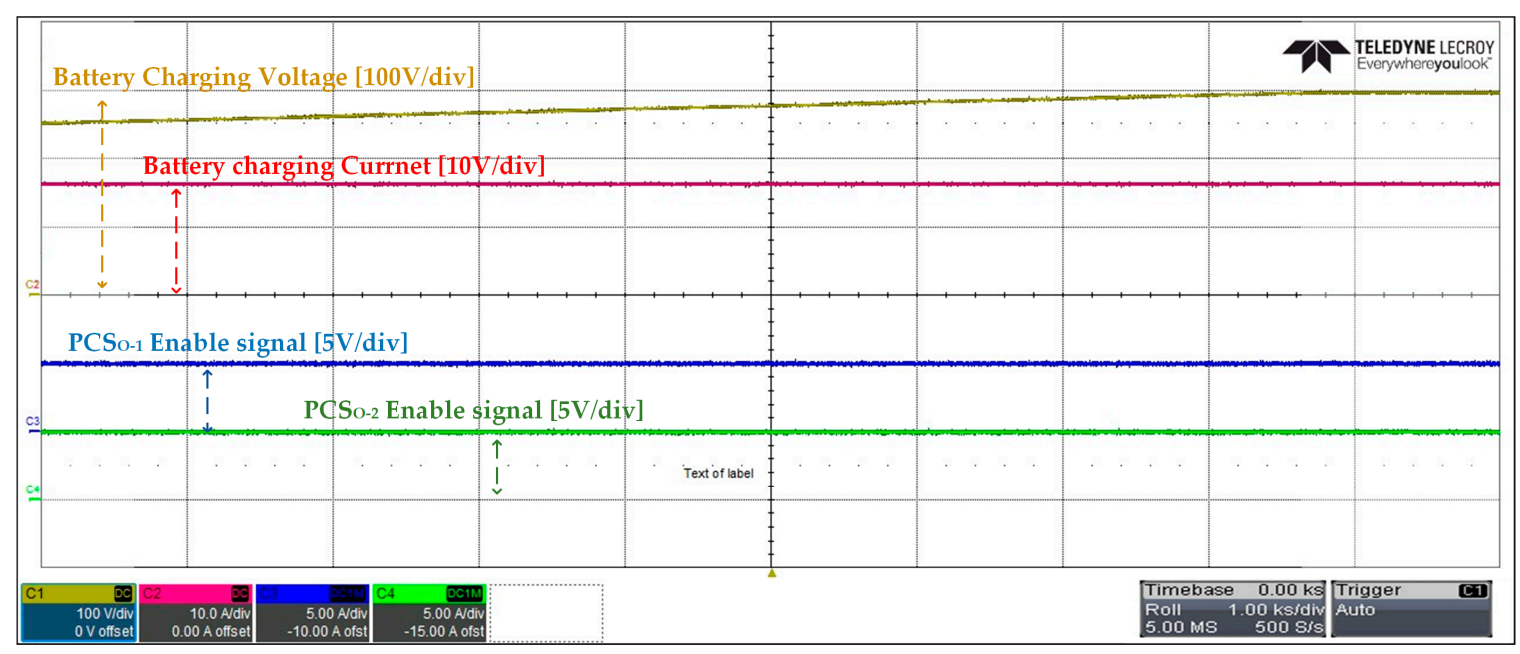

Figure 12. Battery charging with PCS 2 module (battery voltage, charging current, module 1 on, module 2 on).

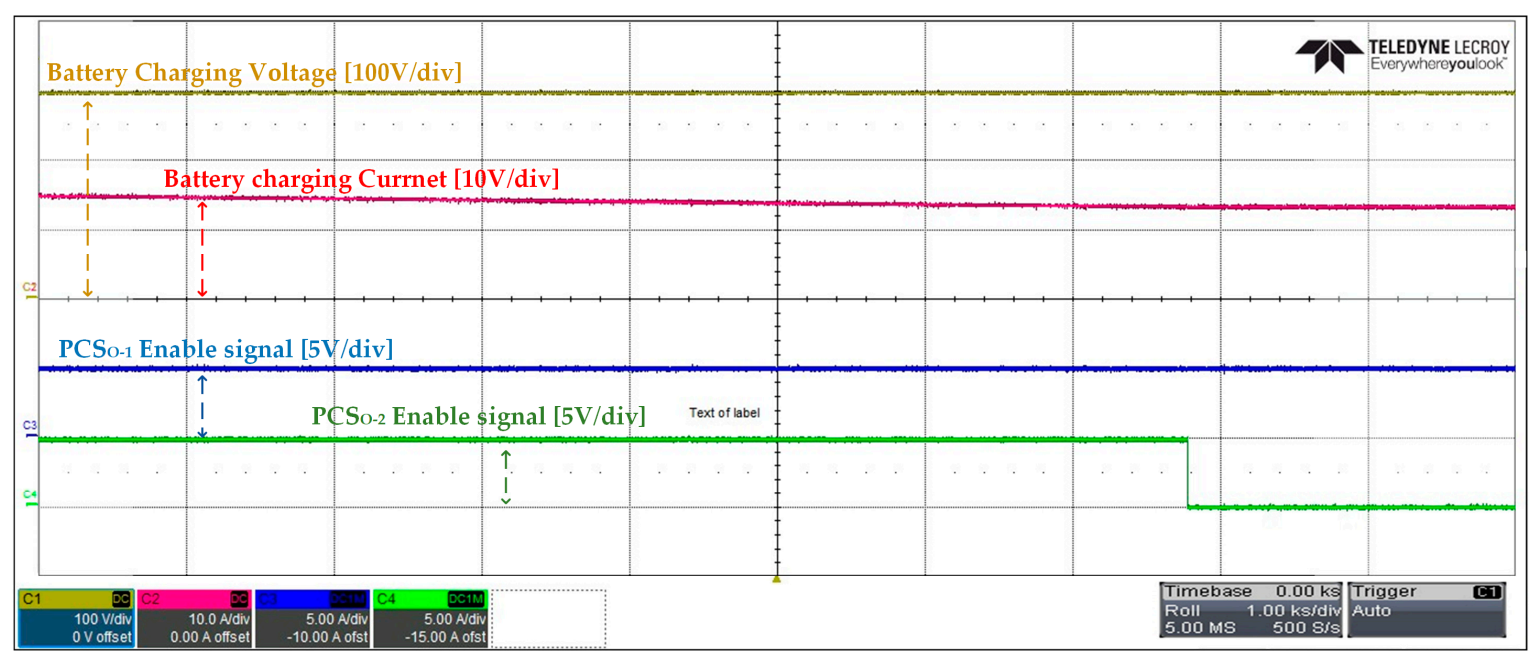

Figure 13. Battery charging with PCS 1 module (battery voltage, charging current, module 1 on, module 2 off).

Figure 14 shows the waveform during battery discharging. Figure 14a shows the maximum module having the waveform of discharging the battery at the maximum C-rate. Thus, the maximum current of each phase flowing to AC grid is 130 A. Figure $14 \mathrm{~b}$ shows the waveform of module disconnection due to the reduced $S o C$. Because the maximum 
capacity of the PCS is used during battery discharging, the PCS is disconnected after the current magnitude reduces upon switching modules.

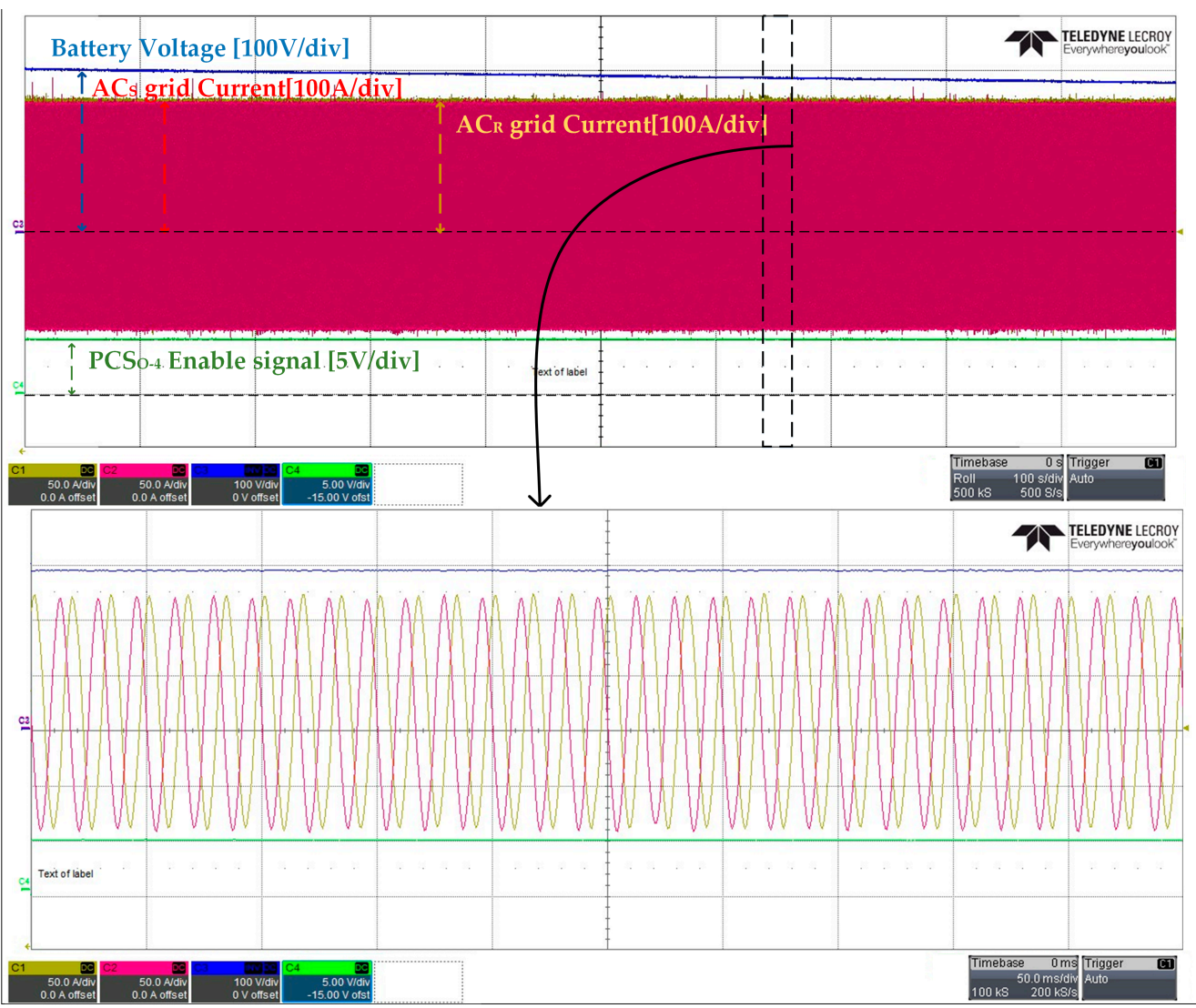

(a)

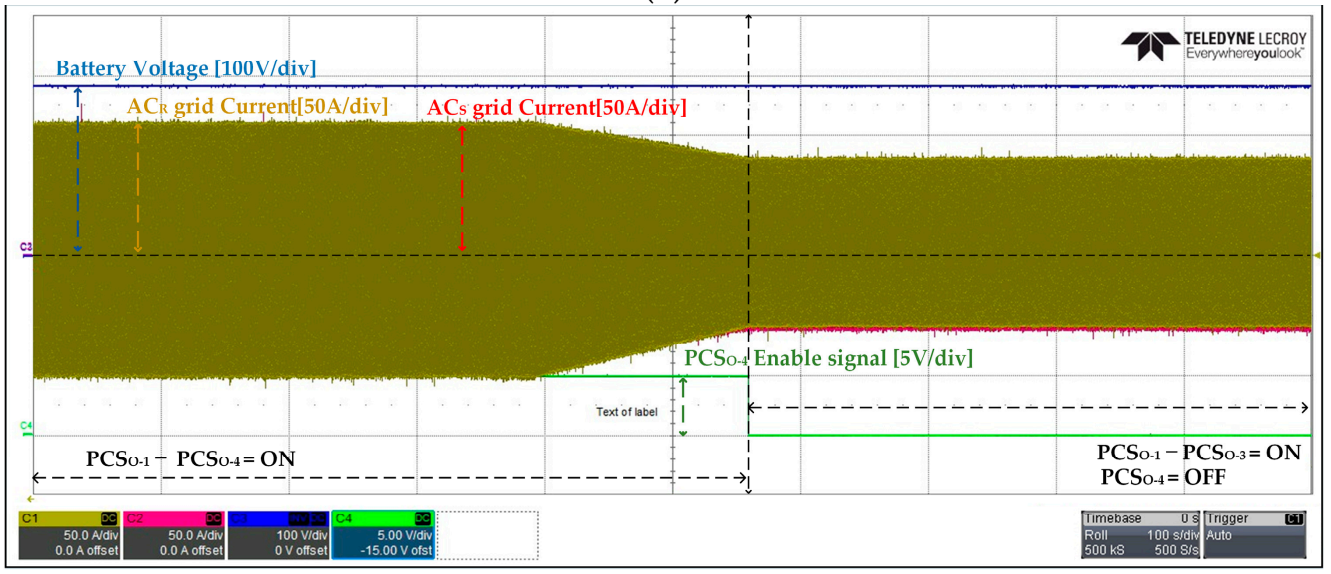

(b)

Figure 14. Waveform during ESS discharge (a) four-parallel PCS operation at maximum C-rate. (b) three-parallel PCS operation due to $\mathrm{SoC}$ reduction.

The signals of $\mathrm{PCS}_{\mathrm{O}-2}$ and $\mathrm{PCS}_{\mathrm{O}-4}$ can be observed because up to two and four modules are used during battery charging and discharging, respectively.

Figure $15 a, b$ shows the daily power generation during the operation of only the ESS and that of an ESS connected with a PV, respectively. 


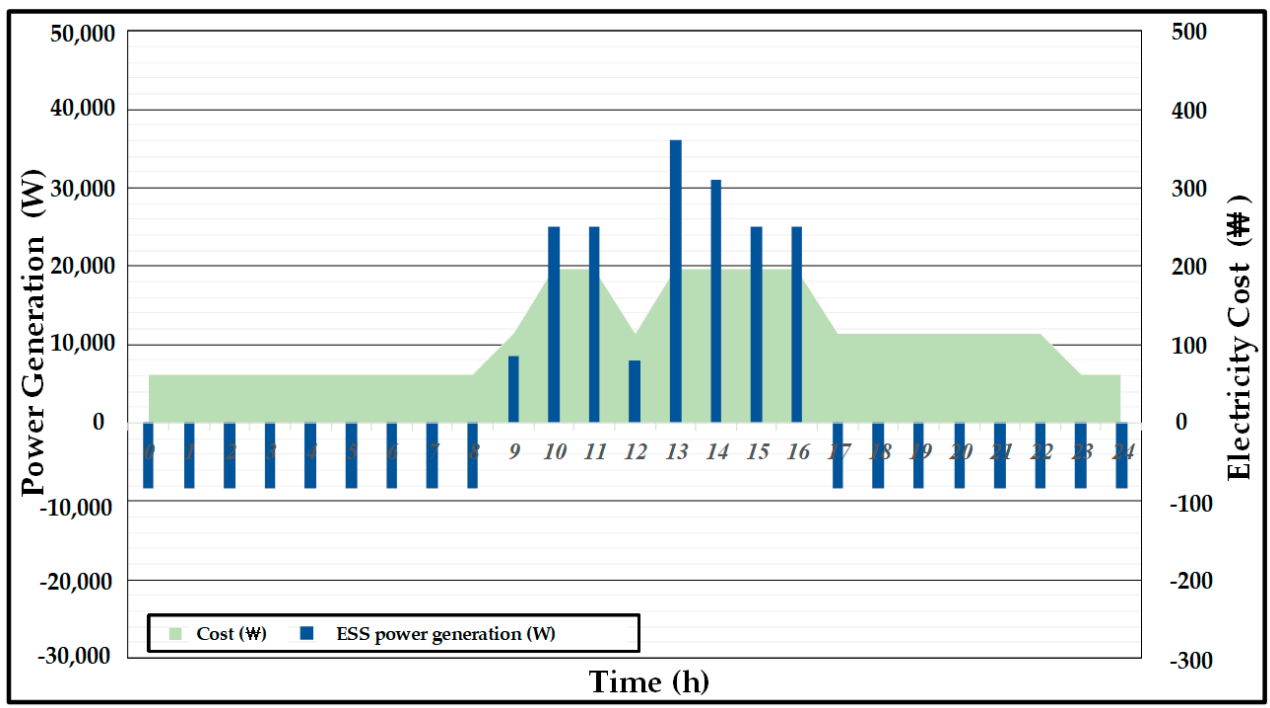

(a)

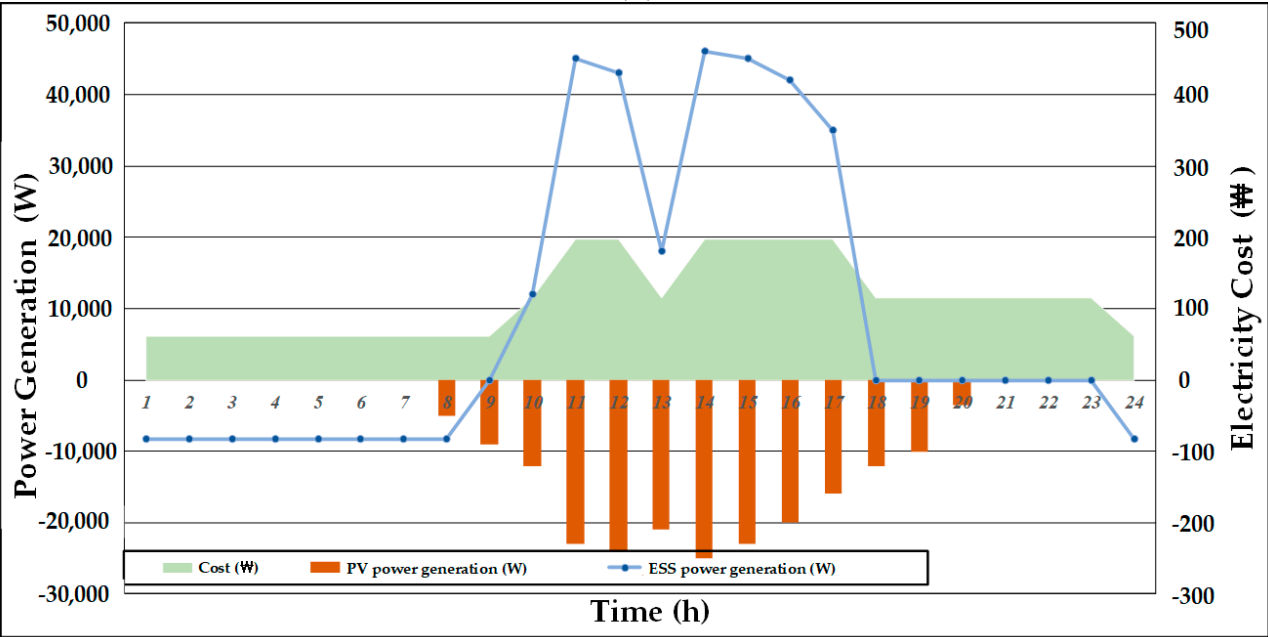

(b)

Figure 15. ESS daily power generation. (a) Only ESS operates. (b) ESS and PV operate.

When only the ESS is adopted, it cannot be operated at the maximum C-rate for $1 \mathrm{~h}$ in electricity rate-based operation due to the lowered SoC. When used in combination with the PV, the PV charges the battery. As a similar operation is attained during the battery charging via solar power and ESS electricity rate, discharging can be performed at the maximum capacity of the PCS. Thus, the ESS may be more effective when used in combination with solar power.

In Figure 15, (+) refers to the increase in the ESS revenue based on inverter operation, and $(-)$ refers to a decrease in profitability due to charging the battery. As the PV is installed to charge the battery, it is marked with $(-)$, as shown in Figure 15a. When the ESS is operated alone, the maximum power generation $(31 \mathrm{kWh})$ occurs at 13:00. However, the ESS is simultaneously discharged at $46 \mathrm{kWh}$ when solar power is employed.

The economic evaluation and PCS operation strategy algorithm proposed in this paper was compared and analyzed with existing studies.

Study [30] used PV and ESS and proposed SoC based optimal scheduling. Study [31] performed peak shaving using PV-BESS. Figure 16 uses PV simulators to provide the same amount of power over time to construct an identical experimental environment. 


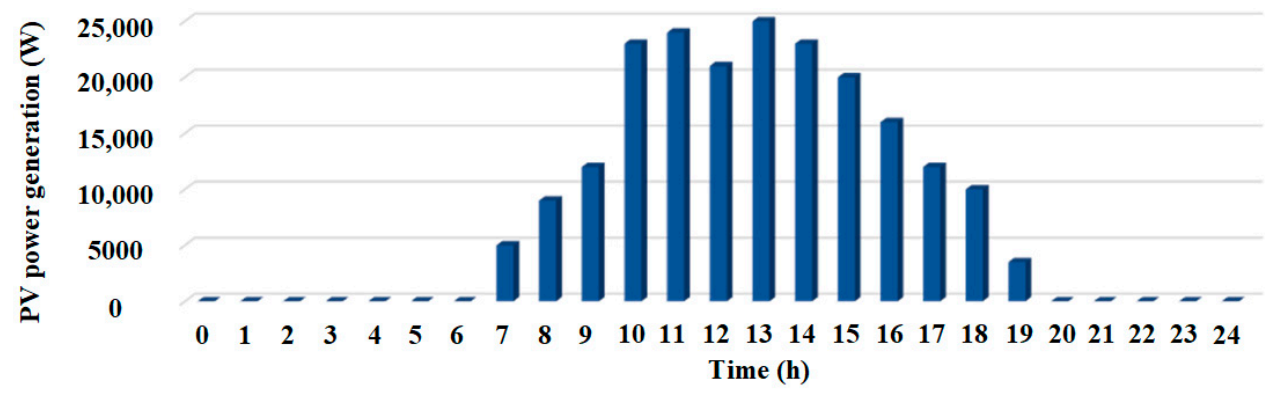

Figure 16. PV output with PV simulator.

Figure 17 shows the comparison of total power generation in ESS.

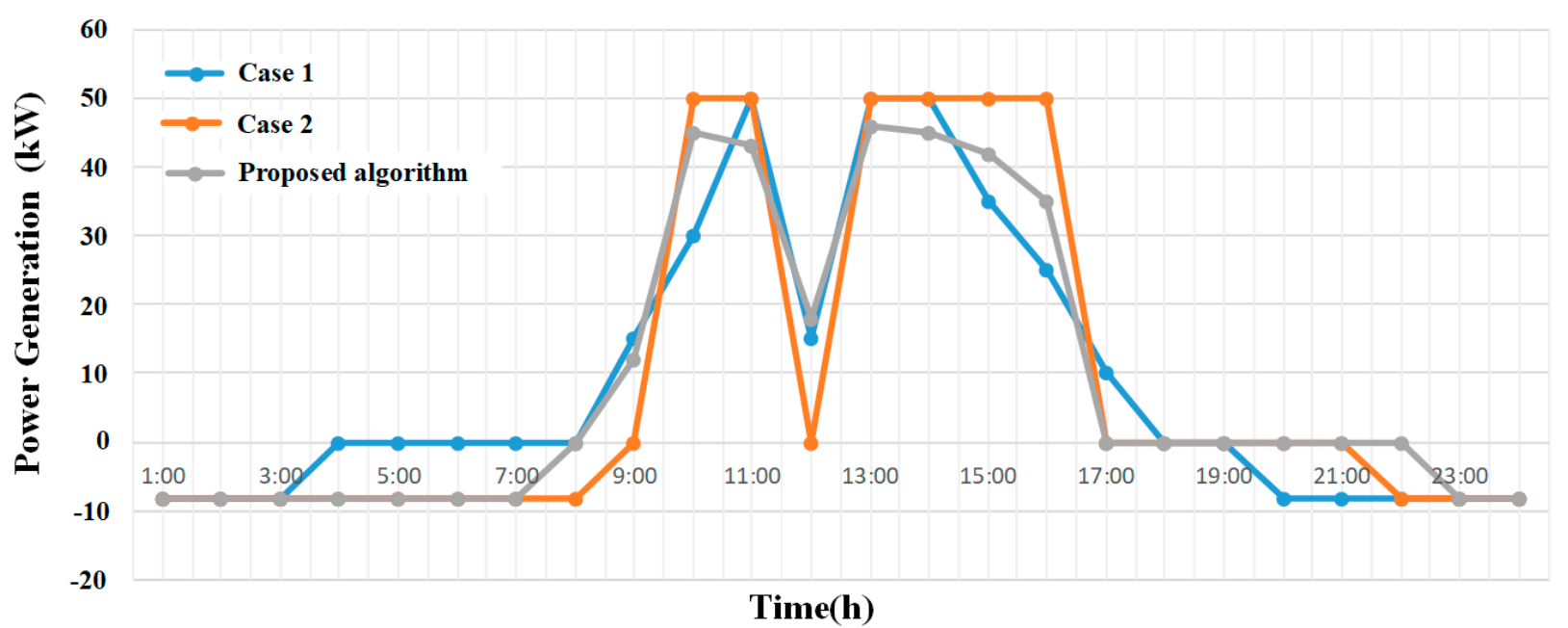

Figure 17. Comparison of total power generation in ESS.

Case 1 is an algorithm with $S o C$ based optimal scheduling, and case 2 is an algorithm with peak shaving.

The algorithm proposed in this paper was compared with a previous study. The amount of charged power is as follows. Case 1: $66.4 \mathrm{kWh}$; case 2: $91.3 \mathrm{kWh}$; proposed algorithm: $74.7 \mathrm{kWh}$. The amount of discharged power is as follows. Case 1: $280 \mathrm{kWh}$; case 2: $208.7 \mathrm{kWh}$; proposed algorithm: $211.3 \mathrm{kWh}$. When these charge/discharge amounts are reflected in the electricity bill of Korea, they are as follows. Case 1: 43,101 won; case 2: 44,707 won; proposed algorithm: 45,222 won.

Table 8 presents the efficiency measurement according to the module operation technique of the PCS. [32] This is a thesis of voltage-source inverters to which the multiinterleaved method is applied. Therefore, the efficiency of a single 50-kW class PCS, a modular PCS with an interleaved method, and the PCS operation algorithm proposed in this paper were measured.

Figure 18 shows the comparison of the PCS operating time when different numbers of modules are used, depending on the battery charging/discharging current, with the number of modules selected based on the operation time and current. $\mathrm{PCS}_{1}-\mathrm{PCS}_{4}$ are commonly used, considering only the magnitude of the current and adding PCS modules beyond a certain current. As these methods are initiated from PCS No. 1, the deviation in the operation time gradually increases. However, because $\mathrm{PCS}_{\mathrm{O}-1}-\mathrm{PCS}_{\mathrm{O}-4}$, using the proposed algorithm, determine the priorities based on the operating time of the PCS, the entire PCS is available for use. 
Table 8. Efficiency measurement according to PCS module operation technique.

\begin{tabular}{cccc}
\hline & \multicolumn{3}{c}{ Efficiency (\%) } \\
\cline { 2 - 4 } Load (\% of $50 \mathbf{k W})(\mathbf{\%})$ & $\begin{array}{c}\text { Single } \\
\text { PCS }\end{array}$ & $\begin{array}{c}\text { Multi-Interleaved } \\
\text { PCS }\end{array}$ & $\begin{array}{c}\text { Proposed PCS Operation } \\
\text { Algorithm }\end{array}$ \\
\hline 5 & 81.50 & 91.30 & 93.50 \\
10 & 93.63 & 93.40 & 95.70 \\
20 & 96.15 & 95.98 & 97.45 \\
30 & 97.87 & 97.20 & 97.40 \\
40 & 97.45 & 97.44 & 97.42 \\
50 & 97.70 & 97.40 & 97.38 \\
60 & 97.40 & 97.39 & 97.4 \\
70 & 97.31 & 97.30 & 97.41 \\
80 & 97.10 & 97.10 & 97.25 \\
90 & 96.85 & 97.00 & 97.35 \\
100 & 96.00 & 96.8 & 96.8 \\
\hline
\end{tabular}

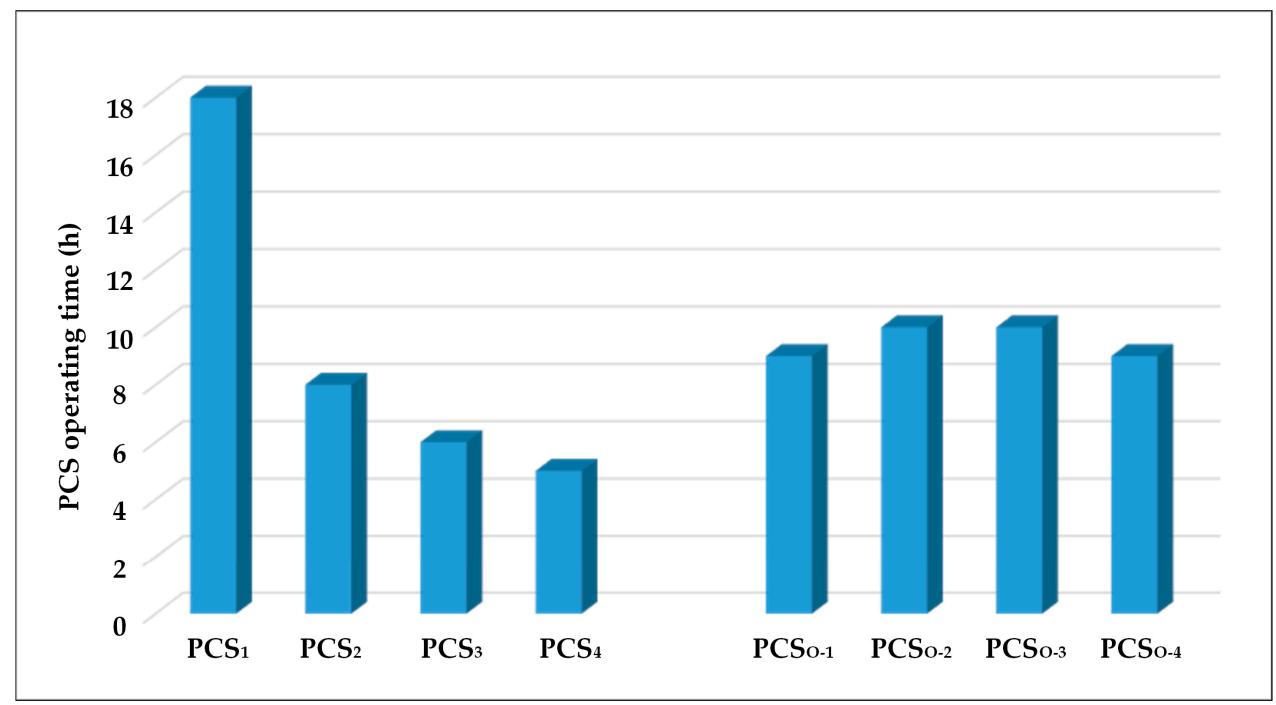

Figure 18. PCS operating time deviation measurement.

\section{Conclusions} in ESSs.

This paper proposes an operation algorithm based on minimizing power charges

The electricity cost is minimized by merging the objective functions of LP and quadratic programming (QP). The proposed approach for cost minimization is based on the charging/discharging efficiency of the PCS. Thus, even if a difference exists between the charging and discharging efficiencies, more accurate electricity cost minimization can be performed.

Comparisons were made according to the ESS's operational techniques to confirm the minimization of power charges. Peak shaving techniques operate at full load, which can maximize power generation revenue. However, due to other charge/discharge C-rates, charging must be started in the mid-load region. This charge hinders minimizing electricity charges. Revenue from each algorithm results in a difference of up to $4.69 \%$, and this difference occurs as the light load conditions increase.

The proposed method also describes the PCS operation algorithm. PCS efficiency by load must be constant to minimize electricity charges and maximize revenue efficiently. Therefore, the algorithm minimizes the efficiency deviation. The efficiency according to the PCS operation algorithm was compared. The PCS operation algorithm proposed in this paper has $97.45 \%$ maximum efficiency and $3.95 \%$ maximum efficiency deviation according to load. For a single PCS, the maximum efficiency is $97.87 \%$ and the maximum efficiency 
deviation under load is $16.37 \%$. Furthermore, the multi-interleaved method, which is used primarily in the multi-parallel structure, has a maximum efficiency of $97.44 \%$ and a maximum efficiency deviation of $6.14 \%$.

The electricity cost of the ESS is minimized based on PCS efficiency. Based on the results, an electricity cost operation of the ESS is performed. The proposed algorithm is validated using a PCS for a $50 \mathrm{~kW}$ class ESS and $25 \mathrm{~kW}$ class PV.

Author Contributions: Conceptualization, J.-M.K. and J.L.; software, J.-W.K.; formal analysis, J.-M.K.; investigation, J.L. and J.Y.; writing—original draft preparation, J.-M.K.; writing—review and editing, J.Y. and C.-Y.W. All authors have read and agreed to the published version of the manuscript.

Funding: This research received no external funding.

Institutional Review Board Statement: Not applicable.

Informed Consent Statement: Not applicable.

Data Availability Statement: Not applicable.

Acknowledgments: This work was supported by the Korea Institute of Energy Technology Evaluation and Planning (KETEP) and Ministry of Trade, Industry \& Energy (MOTIE) of the Republic of Korea (No. 2019381010001B).

Conflicts of Interest: The authors declare no conflict of interest.

\section{References}

1. $\quad$ Andre, T.; Guerra, F. Renewables Global Status Report; REN21: Paris, France, 2020; ISBN 978-3-948393-00-7.

2. Denholm, P.; O'Connell, M.; Brinkman, G.; Jorgenson, J. Overgeneration from Solar Energy in California: A Field Guide to the Duck Chart; National Renewable Energy Lab (NREL): Golden, CO, USA, 2015; NREL/TP-6A20-65023.

3. Castillo, A.; Gayme, D.F. Grid-scale energy storage applications in renewable energy integration: A survey. Energy Convers. Manag. 2014, 87, 885-894. [CrossRef]

4. Mongird, K.; Viswanathan, V.; Alam, J.; Vartanian, C.; Sprenkle, V.; Baxter, R. 2020 Grid Energy Storage Technology Cost and Performance Assessment; U.S. Department of Energy: Washington, DC, USA, 2020.

5. Mongird, K.; Viswanathan, V.V.; Balducci, P.J.; Alam, M.J.E.; Fotedar, V.; Koritarov, V.S.; Hadjerioua, B. Energy Storage Technology and Cost Characterization Report; No. PNNL-28866, Pacific Northwest National Lab. (PNNL): Richland, WA, USA, 2019.

6. Jo, B.-K.; Jang, G. An Evaluation of the Effect on the Expansion of Photovoltaic Power Generation According to Renewable Energy Certificates on Energy Storage Systems: A Case Study of the Korean Renewable Energy Market. Sustainability 2019, 11, 4337. [CrossRef]

7. Nazaripouya, H.; Chu, C.C.; Pota, H.R.; Gadh, R. Battery energy storage system control for intermittency smoothing using an optimized two-stage filter. IEEE Trans. Sustain. Energy 2018, 9, 664-675. [CrossRef]

8. Nishimwe H, L.F.; Yoon, S.G. Combined Optimal Planning and Operation of a Fast EV-Charging Station Integrated with Solar PV and ESS. Energies 2021, 14, 3152. [CrossRef]

9. Bridier, L.; Hernández-Torres, D.; David, M.; Lauret, P. A heuristic approach for optimal sizing of ESS coupled with intermittent renewable sources systems. Renew. Energy 2016, 91, 155-165. [CrossRef]

10. Nimma, K.; Al-Falahi, M.; Nguyen, H.D.; Jayasinghe, S.D.G.; Mahmoud, T.; Negnevitsky, M. Grey Wolf Optimization-Based Optimum Energy-Management and Battery-Sizing Method for Grid-Connected Microgrids. Energies 2018, 11, 847. [CrossRef]

11. Lee, S.; Choi, D.-H. Reinforcement learning-based energy management of smart home with rooftop solar photovoltaic system, energy storage system, and home appliances. Sensors 2019, 19, 3937. [CrossRef] [PubMed]

12. Weniger, J.; Tjaden, T.; Quaschning, V. Sizing of residential PV battery systems. Energy Procedia 2014, 46, 78-87. [CrossRef]

13. Giráldez, J.; Roche, R.; Suryanarayanan, S.; Zimmerle, D. A linear programming methodology to quantify the impact of PHEVs with V2G capabilities on distribution systems. In Proceedings of the 2013 IEEE Green Technologies Conference (GreenTech), Denver, CO, USA, 4-5 April 2013; pp. 8-15.

14. Luna, A.C.; Diaz, N.L.; Graells, M.; Vasquez, J.C.; Guerrero, J.M. Mixed-integer-linear-programming-based energy man-agement system for hybrid PV-wind-battery microgrids: Modeling, design, and experimental verification. IEEE Trans. Power Electron. 2016, 32, 2769-2783. [CrossRef]

15. Fu, B.; Ouyang, C.; Li, C.; Wang, J.; Gul, E. An improved mixed integer linear programming approach based on symmetry diminishing for unit commitment of hybrid power system. Energies 2019, 12, 833. [CrossRef]

16. Delgado, D.; Carvalho, M.; Junior, L.M.C.; Abrahão, R.; Chacartegui, R. Photovoltaic solar energy in the economic optimisation of energy supply and conversion. IET Renew. Power Gener. 2018, 12, 1263-1268. [CrossRef]

17. Gomes, I.L.R.; Melicio, R.; Mendes, V.M.F. A novel microgrid support management system based on stochastic mixed-integer linear programming. Energy 2021, 223, 120030. [CrossRef] 
18. Mao, T.; Zhou, B.; Zhang, X. Accommodating discharging power with consideration of both EVs and ESs as commodity based on a two-level genetic algorithm. IEEE Access 2019, 7, 134804-134814. [CrossRef]

19. Gu, F.; Cheung, Y.M. Self-organizing map-based weight design for decomposition-based many-objective evolutionary al-gorithm. IEEE Trans. Evol. Comput. 2017, 22, 211-225. [CrossRef]

20. Lee, S.-J.; Yoon, Y. Electricity cost optimization in energy storage systems by combining a genetic algorithm with dynamic programming. Mathematics 2020, 8, 1526. [CrossRef]

21. Sedghi, M.; Ahmadian, A.; Aliakbar-Golkar, M. Optimal storage planning in active distribution network considering uncertainty of wind power distributed generation. IEEE Trans. Power Syst. 2015, 31, 304-316. [CrossRef]

22. Shreelakshmi, M.P.; Das, M.; Agarwal, V. Design and development of a novel high voltage gain, high-efficiency bidirectional DC-DC converter for storage interface. IEEE Trans. Ind. Electron. 2018, 66, 4490-4501.

23. Xu, B.; Oudalov, A.; Ulbig, A.; Andersson, G.; Kirschen, D.S. Modeling of lithium-ion battery degradation for cell life as-sessment. IEEE Trans. Smart Grid. 2016, 9, 1131-1140. [CrossRef]

24. Carvalho, E.L.; Felipe, C.A.; Bellinaso, L.V.; Stein, C.M.D.O.; Cardoso, R.; Michels, L. Asymmetrical-PWM DAB Converter with extended ZVS/ZCS Range and Reduced Circulating Current for ESS Applications. IEEE Trans. Power Electron. 2021, 36, 12990-13001. [CrossRef]

25. KEPCO. Electrics Tables. Available online: https://home.kepco.co.kr/kepco/EN/F/htmlView/ENFBHP00101.do?menuCd= EN060201 (accessed on 1 December 2016).

26. KEPCO. ESS Discount System. Available online: https://cyber.kepco.co.kr/ckepco/front/jsp/CY/D/C/CYDCHP00212.jsp (accessed on 25 June 2021).

27. Korea Energy Agency. Renewable Portfolio Standards. Available online: https://dco.energy.or.kr/renew_eng/new/standards. aspx (accessed on 1 January 2012).

28. Kim, K.H.; Hyun, D.S. A high performance DSP voltage controller with PWM synchronization for parallel operation of UPS systems. In Proceedings of the 2006 37th IEEE Power Electronics Specialists Conference, Jeju, Korea, 18-22 June 2006; pp. 1-7.

29. Mohd, A.; Ortjohann, E.; Morton, D.; Omari, O. Review of control techniques for inverters parallel operation. Electr. Power. Syst. Res. 2010, 80, 1477-1487. [CrossRef]

30. Alam, M.M.; Ahmed, M.F.; Jahan, I.; Jang, Y.M. Optimal Energy Management Strategy for ESS with Day Ahead Energy Prediction. In Proceedings of the 2021 International Conference on Artificial Intelligence in Information and Communication (ICAIIC), Jeju Island, Korea, 13-16 April 2021; pp. 492-496.

31. Danish, S.M.S.; Ahmadi, M.; Danish, M.S.S.; Mandal, P.; Yona, A.; Senjyu, T. A coherent strategy for peak load shaving using energy storage systems. J. Energy Storage 2020, 32, 101823. [CrossRef]

32. Capella, G.J.; Pou, J.; Ceballos, S.; Konstantinou, G.; Zaragoza, J.; Agelidis, V.G. Enhanced phase-shifted PWM carrier disposition for interleaved voltage-source inverters. IEEE Trans. Power Electron. 2014, 30, 1121-1125. [CrossRef] 